\title{
Effects of a nurse shrub on seed deposition and seedling recruitment of the annual Agriophyllum squarrosum
}

\author{
F.-R. Li, G. Li, L.-F. Kang, Z.-G. Huang, Q. Wang, J.-L. Liu
}

Li, F.-R., Li, G., Kang, L. F., Huang, Z.-G. and Liu, J. L. 2007. Effects of a nurse shrub on seed deposition and seedling recruitment of the annual Agriophyllum squarrosum. Web Ecology 7: 94-105.

\begin{abstract}
The shrub Artemisia halodendron and the annual herb Agriophyllum squarrosum, which typically co-occur in a mobile sandy habitat in eastern inner Mongolia, China, were used to determine whether the presence of $A$. halodendron influences seed deposition and seedling recruitment of $A$. squarrosum under and around the shrub canopy in relation to wind direction, sampling position (windward vs leeward sides) and distance from the shrub. The numbers of seeds deposited, seedlings emerged, and individuals recruited of $A$. squarrosum around adult shrubs were sampled along four transects aligned to the four main wind directions at $0.5,1,2,3,4.5$ and $6 \mathrm{~m}$ from the shrub base on both windward and leeward sides of each transect. Spatial pattern of seed deposition was strongly altered by the presence of shrubs, but effects varied with wind direction, sampling position and distance from shrubs. Significantly more seeds tended to deposit on the leeward than on the windward sides in all four transects, with the exception of transects along the least prevailing wind direction. The presence of shrubs as nursing plants caused a marked variation in seed deposition across sampling locations, but this effect was detected only in the most, secondary and third most prevailing wind directions, but not in the least prevailing wind direction. In general, the shrub's influence was within a $2 \mathrm{~m}$ radius from the shrub, despite some differences among transects. Although seed bank density had no direct effect on $A$. squarrosum recruitment patterns, it contributed to the observed variation in recruitment indirectly through density-dependent emergence of seedlings. Our findings provide further evidence of shrubs as a source of spatial heterogeneity in seed availability and thereby a common factor determining population dynamics of understorey herbaceous species.
\end{abstract}

Li,F.-R. (lfengrui@vip.163.com),Kang, L.F., Huang, Z.-G. and Liu, J. L., Chinese Ecosystem Network Res. Naiman Desertfication Res. Station, Cold and Arid Regions Environ. and Engineering Res. Inst., Chinese Acad. of Sciences, 260 Donggang West Road, Lanzhou, CN730000, China. - Li, G., E H Graham Centre for Agricultural Innovation, Wagga Wagga Agricultural Inst., PMB, Wagga Wagga, NSW 2650, Australia.

Spatial heterogeneity in seed availability is regarded as a major factor determining the spatial pattern of plant populations and communities (Henderson et al. 1988, Kemp 1989, Aguiar and Sala 1997, Nathan and MullerLandau 2000). Many biotic and abiotic factors may generate spatial heterogeneity in seed availability in natural ecosystems, such as trapping of secondary wind-dispersed seeds by woody species (shrubs/trees) (Bullock and Moy 2004), patchy distribution of plant populations within heterogeneous landscapes (Russell and Schupp 1998, Orrock et al. 2006), and seed predation (i.e. seed predators removed seeds from one place to another) (Russell 
and Schupp 1998, Honek et al. 2005). A combination of these factors is most likely to render differently scaled heterogeneity of seed availability from landscapes (Orrock et al. 2006) to a community patch (Russell and Schupp 1998).

The ecological role of woody species as a source of spatial variation in abiotic environmental conditions in arid and semi-arid ecosystems has received much attention in the last few decades (Charley and West 1975, Barth and Klemmedson 1978, Belsky et al. 1989, Frost and Edinger 1991, Hook et al. 1991, Rosagno et al. 1991, Vetaas 1992, Gutiérrez et al. 1993, Cross and Schlesinger 1999), and is now well recognized. However, the ecological role of woody species as a source of spatial variation in seed deposition and seedling recruitment of herbaceous species in the understorey has received less attention (Callaway 1992, Vetaas 1992, Moro et al. 1997, Pugnaire and Lázaro 2000, López-Pintor et al. 2006). A fundamental question remains, however, as to how the presence of individual shrubs may cause a fine-scale variation in seed deposition, and how such shrub-induced variations in seed bank density further affect the patterning of seedling recruitment in herbaceous species.

There are at least three possible ways by which adult shrubs have a significant influence on their understorey herbaceous species. Firstly, an adult shrub could act as a physical barrier to significantly influence local wind dynamics in the immediate vicinity of the shrub canopy (Seginer 1975), and consequently alter the spatial pattern of seed deposition by the redistribution of wind-dispersed seeds (Ben-Natan et al. 2004). Secondly, adult shrubs have been known to have neighbourhood effects (Fowler 1984), acting as either a nurse plant (Franco and Nobel 1989, Shumway 2000, Barchuk et al. 2005, Gómez-Aparicio et al. 2005) or a potential competitor (Dyer et al. 2000, Facelli and Temby 2002, Maestre et al. 2003, Miriti 2006), on seedling emergence and recruitment of herbaceous species under and around shrub canopies. Thirdly, shrub-induced variation in seed availability (seed bank density) might also have an indirect effect on population dynamics of herbaceous species through density-dependent emergence and recruitment of individuals (Inouye 1980, Bergelson and Perry 1989, Murray 1998, Orth et al. 2003, Li et al. 2005a, Tielbörger and Valleriani 2005).

We used a shrub, Artemisia halodendron (Asteraceae), and an annual herb, Agriophyllum squarrosum Moq. (Chenopodiaceae), which typically co-occur in a severely degraded mobile sandy habitat, as a case study to address the following questions: 1) does the presence of $A$. halodendron shrubs influence the dynamics of soil seed bank and seedling recruitment of $A$. squarrosum under and around shrubs? 2) Do wind direction, sampling position relative to the shrubs (windward vs leeward sides) and distance from the shrub affect seed deposition and recruitment of $A$. squarrosum? 3) What is the relationship between seed deposition, seedling emergence and recruitment of $A$. squarro- sum populations under different wind directions? The information from this study is important for improving our understanding of evolutionary and ecological significance of woody species as a driver of herbaceous vegetation succession and ecosystem functioning change.

\section{Material and methods}

\section{Study site and plant species}

The study was conducted in a mobile sandy habitat at the Selihu nature reserve $\left(42^{\circ} 55^{\prime} \mathrm{N}, 120^{\circ} 44^{\prime} \mathrm{E}\right.$; $360 \mathrm{~m}$ a.s.l.) located in the Horqin Sandland of eastern inner Mongolia, China, approximately $500 \mathrm{~km}$ northeast of Beijing. The climate is temperate, semi-arid and continental, with average annual precipitation of $343 \mathrm{~mm}$ (1978-2003), of which $75 \%$ falls during the summer (June to September). Scant rains and frequent winds between November and May makes this period the major wind-erosion season ( $\mathrm{Li}$ et al. 2003) and the potential dispersal season for seeds (diasporas) (Li et al. 2005b). The prevailing winds during this period are north-westerly and westerly, but there is high inter-annual variation in wind regimes (Zhang et al. 2004a). The vegetation was composed of only a few pioneer annuals, with $A$. squarrosum being the most abundant species in the herbaceous layer. Populations of the shrub $A$. halodendron were scattered sparsely in the herbaceous matrix (Li et al. 2005c).

In the study area, $A$. squarrosum seeds start to germinate in May after a significant rain, with a peak of seedling emergence in June. Plants flower in mid August, set seeds between late August and early September, and seeds mature in late September. Seeds are mainly dispersed by wind (Li et al. 1992). A laboratory germination experiment showed no evidence of seed dormancy of this species, as the yearly harvested mature seeds can germinate at any time under favourable water and temperature conditions (Cui et al. 2007). As a pioneer species, A. squarrosum can readily colonise and establish in highly unstable, nutrientpoor mobile sands where few species can survive. The successful colonization of this species has been proposed to be the result of its ability to exploit infertile sandy soils as well as its capacity to produce a large number of offspring through seedling recruitment (Li et al. 1992). Nemoto and $\mathrm{Lu}$ (1992) revealed that after germination, the embryo of A. squarrosum can develop into a taproot system, which supports the seedlings against wind and extracts moisture and nutrients from relatively deep soil layers. Therefore, this species is commonly regarded as a key species, playing an important role in driving the restorative succession of psammophytic vegetation in degraded sandy ecosystems by stabilizing mobile sands and creating microhabitats favourable for the colonization and establishment of subsequent plant species (Chang et al. 1994). 


\section{Data collection and data analysis}

In March 2002, six adult $A$. halodendron individuals of similar canopy size of approximately $72.2 \pm 9.8 \mathrm{~cm}$ (mean $\pm S D$ ) in height and $278.2 \pm 22.9 \mathrm{~cm}$ in canopy diameter were chosen in a 2 ha area as 'target shrubs'. Each target shrub was selected to ensure that it was singular within a patch in a 30-m radius without conspecific and allospecific shrubs. For each target shrub, four transects were set up aligned to the four main wind directions. Each transect consisted of the windward side (with leading wind direction) and the leeward side (with minor wind direction) centred on each target shrub. Six sampling locations were placed at distances of $0.5,1,2,3,4.5$ and $6 \mathrm{~m}$ from the base of the shrubs on both windward and leeward sides of a transect. The sampling location at $6 \mathrm{~m}$ from the shrub was regarded as a control that is beyond the influence of the shrub canopy.

At each location, a soil seed bank sample of $20 \times 20 \mathrm{~cm}$ and $5 \mathrm{~cm}$ deep was taken prior to seed germination in the first week of April in 2002. This sampling depth was considered appropriate as over $70 \%$ of the seeds were found in this layer (Zhao et al. 2003). In addition, A. squarrosum seeds deposited at the top few centimetres of soil are expected to be redistributed by wind-driven secondary dispersal (Yan et al. 2005). Thus, the pattern of seed deposition observed at the time of taking the soil samples was assumed to be a result of the combined effects of winds occurring in different directions over the dispersal period between late October 2001 (after primary dispersal) and early April 2002. The direct germination method was used to determine the size of viable seed banks in $A$. squarrosum (Gross 1990). The samples were placed in plastic trays. The trays were first filled with seed-free sand about $70 \mathrm{~mm}$ deep, and then the samples were spread to form a uniform, thin layer (4-6 $\mathrm{mm})$ and covered with 1-2 $\mathrm{mm}$ of seed-free fine sand. Trays were germinated in an unheated glasshouse and the viable seed bank size was estimated from counts of seedlings that emerged over the 12week period. During the germination, the trays were watered regularly and emergent seedlings were monitored twice a week and seedlings were removed after species were identified. More details of the germination experiment can be found in Li et al. (2005b). At each location, the numbers of seedlings emerged and plants recruited were also monitored using a $1 \times 1 \mathrm{~m}$ quadrat in close vicinity to the seedbank sampling locations $(25 \mathrm{~cm}$ apart $)$ at late June and late August (late stages of the growing season), respectively.

Time series of wind velocity and direction were recorded at $2 \mathrm{~m}$ above the ground with an automatic anemometer at a minute interval during the dispersal period from late October 2001 to early April 2002.

The main effects of wind direction (transect), sampling position (windward vs leeward sides of the shrub) and distance from the shrub, as well as their interactions on seed deposition, seedling emergence and plant recruitment were first tested with a three-way Anova. Since a highly significant 3-way interaction between wind direction, sampling position and distance from the shrub on each of the three response variables, separate Anova:s were therefore conducted within each wind direction (each transect). Data for all three response variables were $\log (\mathrm{x}+1)$ transformed prior to analysis to achieve homogeneity and normal distribution of variances. Tukey post-hoc tests were used to test for differences in each response variable between 1) the four transects, 2) the windward and the leeward sides of the shrub and 3) the six sampling locations on each side of a transect. Path and regression analyses were performed to determine the direct and indirect effects

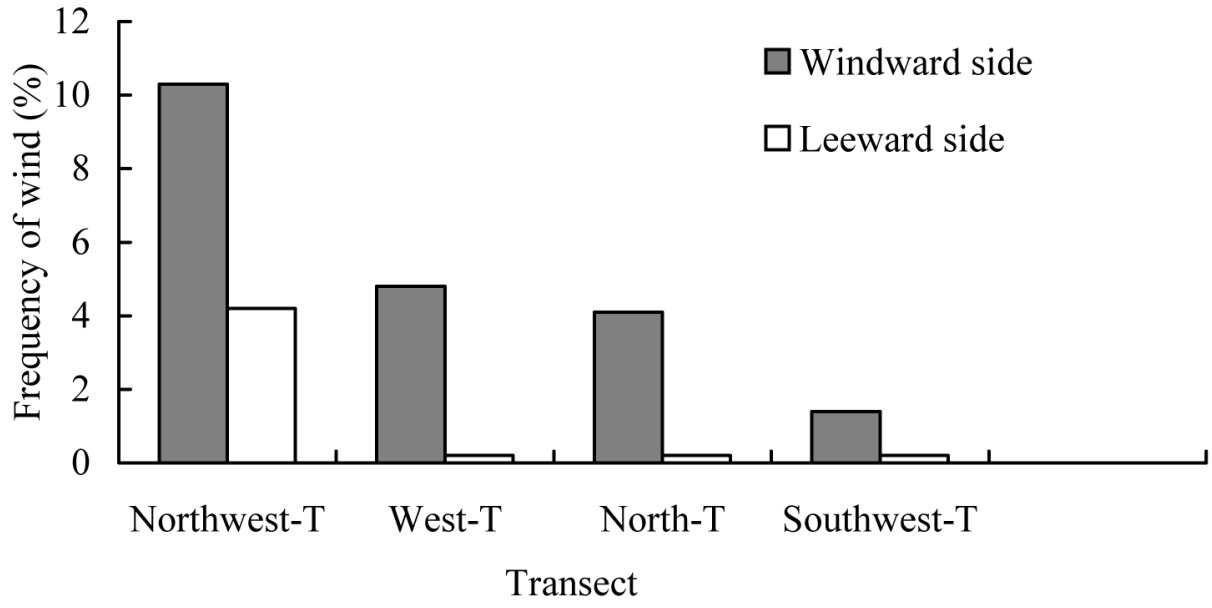

Fig. 1. Frequency (\%) of wind that occurred with velocity $\geq 4 \mathrm{~m} \mathrm{~s}^{-1}$ at $2 \mathrm{~m}$ height during the dispersal period between late October 2001 (after primary dispersal) to early April 2002 (before taking the seedbank samples) on both windward and leeward sides of the four transects. Definitions of Northeast-T, Southeast-T, West-T, and North-T are given in Table 2. 
of seed density and seedling emergence on $A$. squarrosum recruitment as well as the relationship between seed deposition and emergence of seedlings from the seed bank within each of the four transects. All statistical analyses were conducted with Genstat Release 9.1 (Lawes Agricultural Trust 2006).

\section{Results}

\section{Wind conditions of the transects}

A wind velocity of $4 \mathrm{~m} \mathrm{~s}^{-1}$ at $2 \mathrm{~m}$ height was regarded as the threshold to initiate the movement of sand in the study area ( $\mathrm{Li}$ et al. 2003). The frequency of the wind (with velocity $\geq 4 \mathrm{~m} \mathrm{~s}^{-1}$ at $2 \mathrm{~m}$ height) over the dispersal period between late October 2001 and early April 2002 was therefore calculated for each of the four transects on both windward and leeward sides (Fig. 1). Wind conditions varied remarkably among transects, with the most prevailing wind direction in the northwest transect and the least prevailing wind direction in the southwest transect. In each transect, the side with higher wind frequency was regarded as windward side and the opposite side as leeward side, but the magnitude of the difference between both sides varied among transects (Fig. 1).

\section{Seed deposition}

Deposition pattern of $A$. squarrosum seeds was strongly influenced by the presence of shrubs, but effects varied depending strongly on wind direction, sampling position and distance from the shrub (Table 1). Overall, much more seeds were deposited on the leeward side than on the windward side in all four transects, especially in the most, secondary and third most prevailing wind directions (Fig.
2). This pattern was also observed when pooled all four transects together (Fig. 2).

The shrub-induced among-location variation varied among sampling transects as well as between the windward and the leeward side of the shrub (Fig. 3). In general, the presence of shrubs resulted in a marked among-location variation in seed deposition in the northwest, west and north transects (Fig. 3a-c), but this effect was not detected in the southwest transect with the least prevailing wind direction (Fig. 3d).

\section{Seedling emergence and plant recruitment}

Emergence of $A$. squarrosum seedlings around the shrubs varied remarkably with wind direction (transect), sampling position and distance from the shrub (Table 1). Although there was a tendency towards higher seedling emergence on the windward side than on the leeward side in all four transects, this effect was no significant except in the northwest and southwest transects (Fig. 2). Pooling all four transects together, there was significantly higher number of seedlings emerged on windward than on leeward sides of the shrub (Fig. 2). The effects of distance on emergence of seedlings within each side of each transect varied remarkably among wind directions (Fig. 4). Across the four transects, no differences in seedling emergence were found among any of the sampling locations on the leeward side, but on the windward side there was a significantly lower number of seedlings emerged at the location closest to the shrub than at the other locations away from shrubs, indicating a negative effect of shrubs on emergence of $A$. squarrosum seedlings (Fig. 4e).

Post-emergence seedling establishment was also strongly influenced by wind direction, sampling position and distance from the shrub (Table 1). Like seedling emergence, there was a consistently higher number of plants recruited on windward than on leeward sides in all four

Table 1. Anova:s for the effects of wind direction, sampling position (windward vs leeward sides) and distance from the shrub on seed deposition (number of seeds deposited), seedling emergence (number of seedlings emerged) and plant recruitment (number of plants recruited) in the annual herb Agriophyllum squarrosum.

\begin{tabular}{|c|c|c|c|c|c|c|c|}
\hline \multirow[b]{2}{*}{ Factor } & \multirow[b]{2}{*}{ DF } & \multicolumn{2}{|c|}{ Seed deposition } & \multicolumn{2}{|c|}{ Seedling emergence } & \multicolumn{2}{|c|}{ Plant recruitment } \\
\hline & & MS & $\mathrm{F}$ & MS & $\mathrm{F}$ & MS & $\mathrm{F}$ \\
\hline Wind direction (WD) & 3 & 4.27 & $6.20^{* * *}$ & 3.85 & $10.30^{* * *}$ & 1.90 & $6.04^{* * *}$ \\
\hline Position $(\mathrm{P})$ & 1 & 15.30 & $22.24^{* * *}$ & 7.51 & $20.07^{* * *}$ & 5.82 & $18.45^{* * *}$ \\
\hline Distance (D) & 5 & 7.38 & $10.74^{* * *}$ & 1.74 & $4.66^{* * *}$ & 2.39 & $7.58^{* * *}$ \\
\hline $\mathrm{WD} \times \mathrm{P}$ & 3 & 1.93 & $2.80^{*}$ & 0.88 & 2.36 & 0.33 & 1.04 \\
\hline $\mathrm{WD} \times \mathrm{D}$ & 15 & 2.10 & $3.05^{* * *}$ & 0.88 & $2.35^{* *}$ & 0.93 & $2.93^{* * *}$ \\
\hline $\mathrm{P} \times \mathrm{D}$ & 5 & 0.12 & 0.17 & 0.21 & 0.57 & 0.87 & $2.77^{*}$ \\
\hline $\mathrm{WD} \times \mathrm{P} \times \mathrm{D}$ & 15 & 3.35 & $4.87^{* * *}$ & 1.21 & $3.24^{* * *}$ & 0.84 & $2.68^{* * *}$ \\
\hline Residual & 240 & 0.68 & & 0.37 & & 0.31 & \\
\hline
\end{tabular}

${ }^{*} \mathrm{p}<0.05,{ }^{* *} \mathrm{p}<0.01,{ }^{* * *} \mathrm{p}<0.001$ 

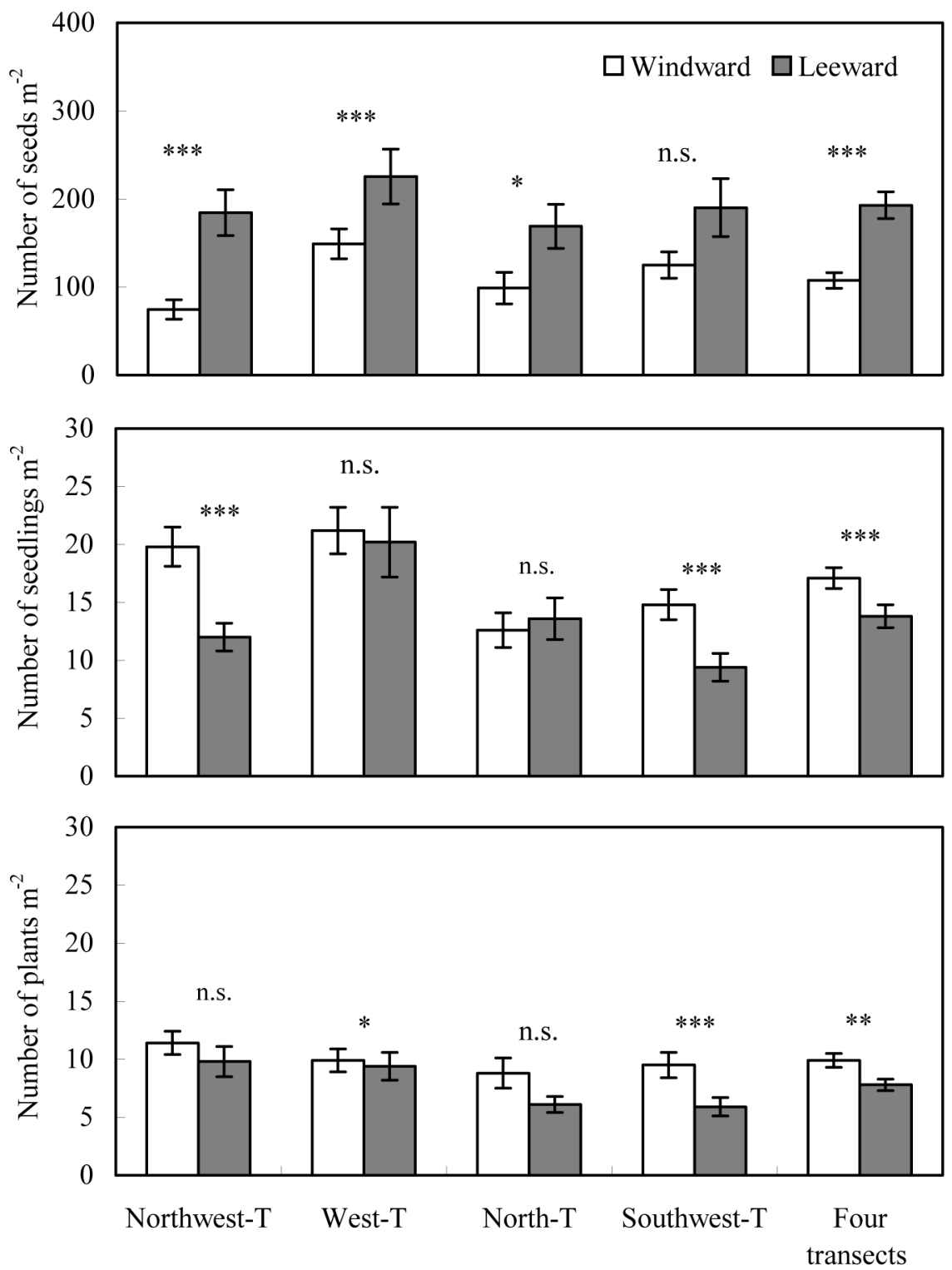

Fig. 2. Mean $( \pm S E)$ numbers of seeds deposited, seedlings emerged and plants recruited in the annual herb A. squarrosum on the windward and leeward sides of the four transects as well as pooling all four transects together. Asterisks indicate significant differences between the windward and the leeward side of a transect (Tukey's tests). ${ }^{*} \mathrm{p}<0.05,{ }^{* *} \mathrm{p}<0.01,{ }^{* * *} \mathrm{p}<0.001$, ns $=$ not significant. Definitions of Northeast-T, Southeast-T, West-T, and North-T are as in Table 2.

transects, but this effect was statistically significant only in two out of the four transects. The effects of distance on recruitment on each side of each transect varied with wind direction and sampling position (Fig. 5). No nurse effect was found in all four transects, but a negative effect of the shrubs on the survival of understorey $A$. squarrosum seedlings was observed in the windward side of the four transects (except for the least prevailing wind direction) and in the leeward side of the west transect (Fig. 5). Pooling all four transects together, no differences were found between any of the sampling locations on the leeward side, but there was a marked negative effect of the shrubs on recruitment of understorey $A$. squarrosum seedlings on the windward side (Fig. 5e).

\section{Spatial concordance among seed density, seedling emergence and recruitment}

There was a significant quadratic relationship between seed density and seedling emergence in the northwest $\left(R^{2}\right.$ 

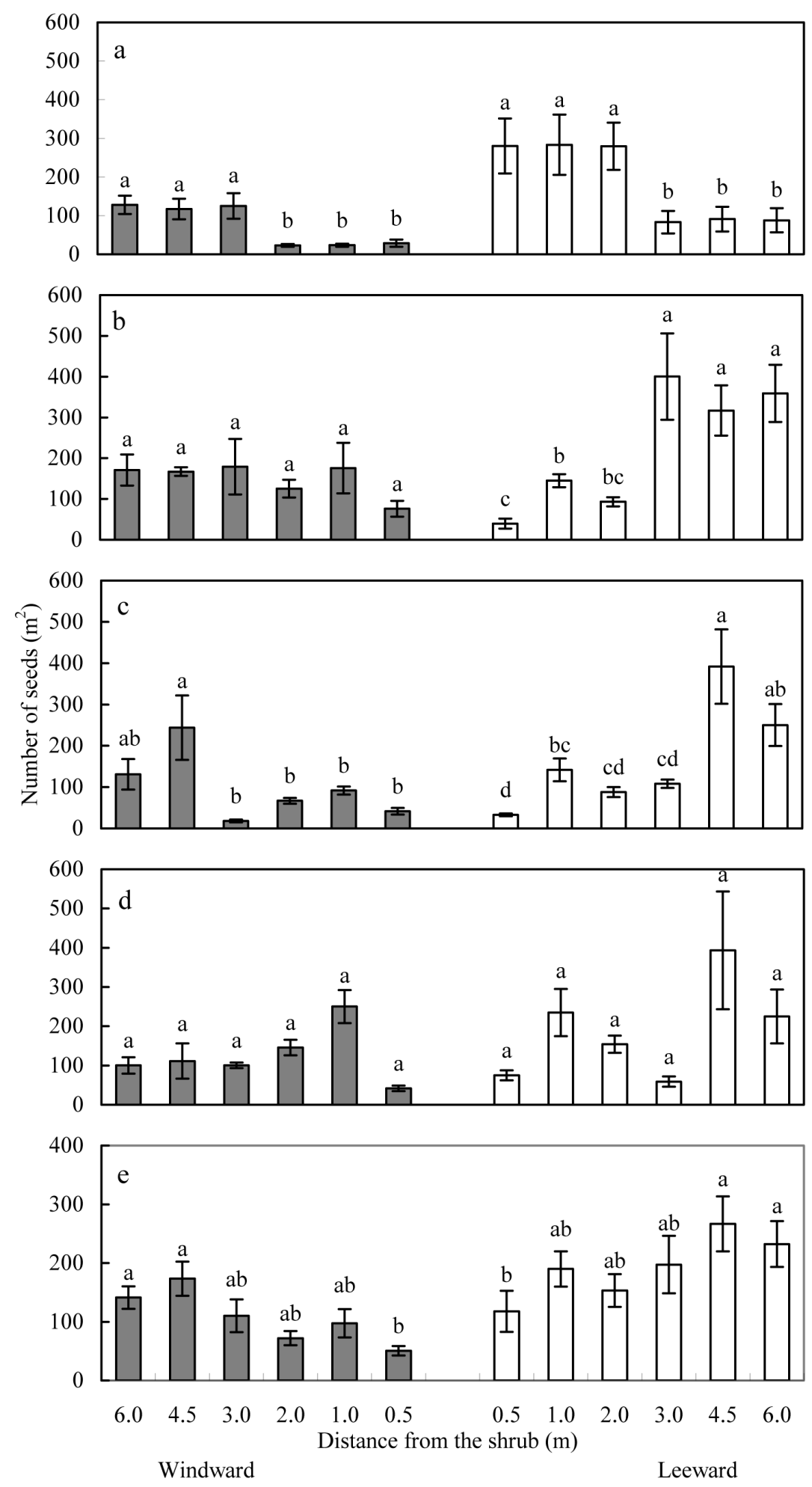

Fig. 3. Mean $( \pm S E)$ number of seeds deposited in six sampling locations on both windward and leeward sides of the four transects. Different letters above the bars indicate significant differences between the six sampling locations within each side of a transect ( $\mathrm{p}<$ 0.05 from Tukey's tests). (a) Northwest-T, (b) West-T, (c) North-T, (d) Southwest-T, and (e) Pooling all four transects together. Definitions of Northeast-T, Southeast-T, West-T, and North-T are as in Table 2. 

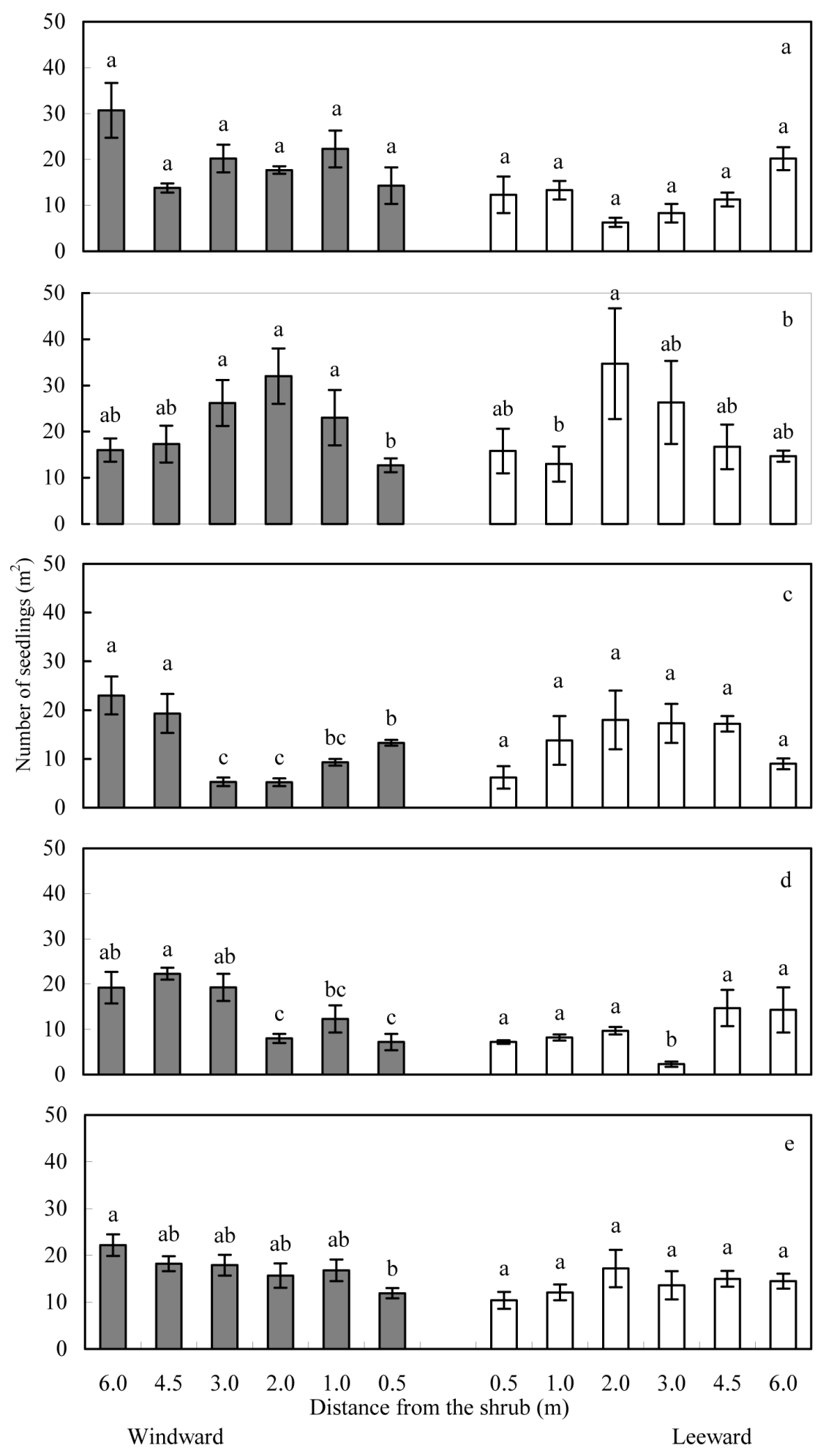

Fig. 4. Mean $( \pm S E)$ number of seedlings emerged in six sampling locations on both windward and leeward sides of the four transects. Different letters above the bars indicate significant differences between the six sampling locations within each side of a transect ( $\mathrm{p}<$ 0.05 from Tukey's tests). (a) Northwest-T, (b) West-T, (c) North-T, (d) Southwest-T, and (e) Pooling all four transects together. Definitions of Northeast-T, Southeast-T, West-T, and North-T are as in Table 2. 

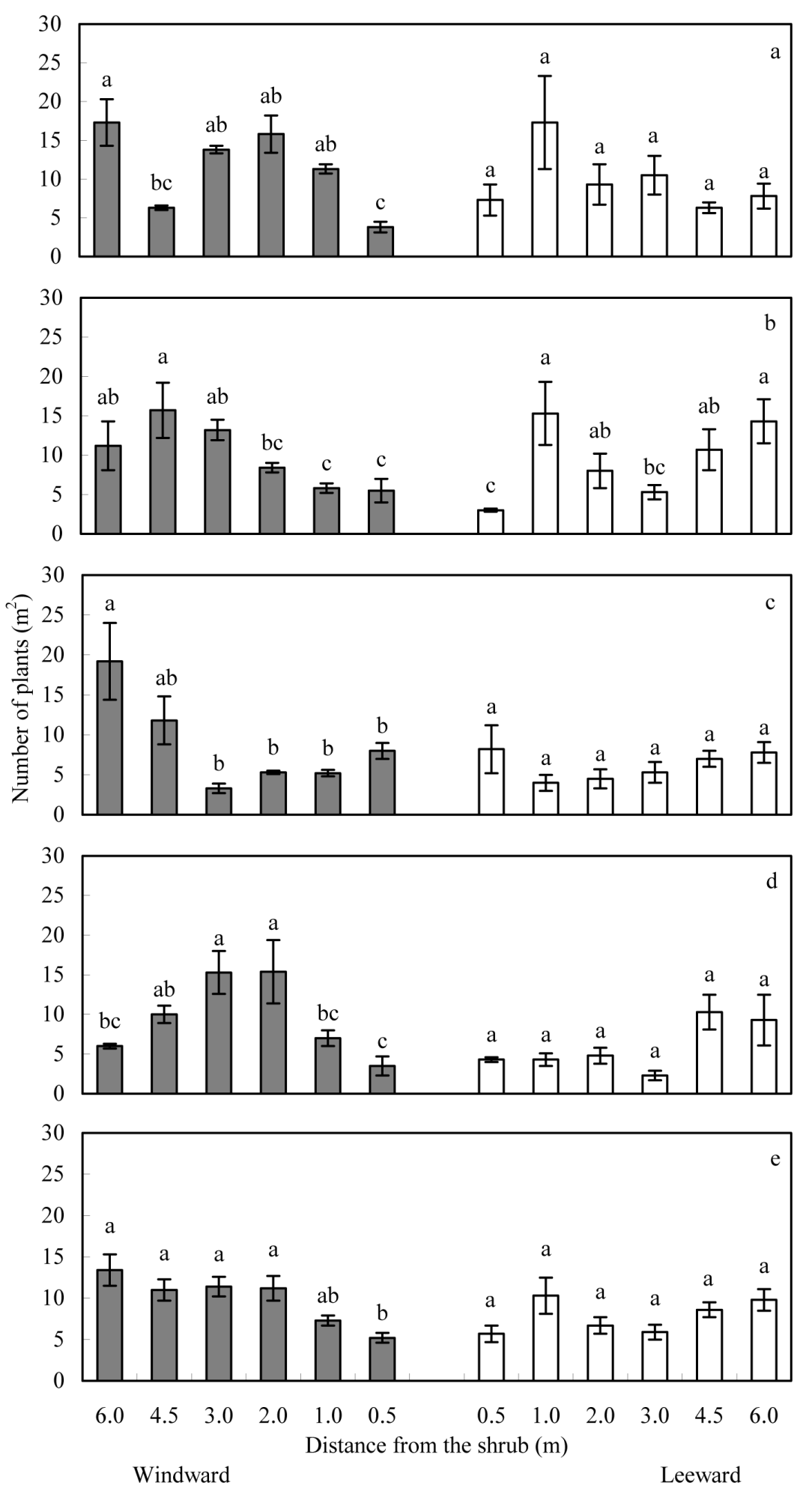

Fig. 5. Mean $( \pm S E)$ number of plants recruited in six sampling locations on both windward and leeward sides of the four transects. Different letters above the bars indicate significant differences between the six sampling locations within each side of a transect $(\mathrm{p}<$ 0.05 from Tukey's tests). (a) Northwest-T, (b) West-T, (c) North-T, (d) Southwest-T, and (e) Pooling all four transects together. Definitions of Northeast-T, Southeast-T, West-T, and North-T are as in Table 2. 
$=0.288, \mathrm{n}=72, \mathrm{p}<0.0001)$ and southwest transects $\left(\mathrm{R}^{2}=\right.$ $0.121, \mathrm{n}=72, \mathrm{p}=0.012)$. This quadratic relationship was also observed when pooled all four transects together $\left(\mathrm{R}^{2}=\right.$ 0.067, $\mathrm{n}=288, \mathrm{p}<0.01)$. Path analysis within transects showed that there was a highly significant positive direct effect of seedling density on recruitment, but the direct effect of seed density on recruitment was not significant except in one out of the four transects (Table 2). Neither seed density nor seedling emergence had an indirect effect on recruitment in all four transects. Path analysis of the pooled data for all four transects showed a highly significant positive direct effect of seedling emergence on recruitment (Table 2).

\section{Discussion}

\section{Effects of shrubs on seed bank dynamics}

The presence of $A$. halodendron shrubs in the mobile sandy habitat had a significant impact on the redistribution of $A$. squarrosum seeds and thereby is a source of spatial heterogeneity in seed availability of herbaceous species in the understorey. This finding is in agreement with the observa- tion of Ben-Natan et al. (2004), who reported that the experimental establishment of an artificial wind barrier made of shadow-cloth in the semi-stabilized sandy habitat resulted in local-scale variation in seed availability by the redistribution of sand and seeds. Our result is also consistent with the observation of $\mathrm{Li}$ (2007) at the same site, who reported that the presence of $A$. halodendron shrubs exerted an important influence on the dynamics of soil seed banks of understorey herbaceous community.

The observed shrub effects appeared mostly due to a physical effect of the shrub canopy (López-Pintor et al. 2006). According to Seginer (1975) and Schurr et al. (2005), an adult individual of shrub species as a natural barrier or obstacle may significantly affect wind dynamics and in particular create the turbulence in the immediate vicinity of the shrub canopy, and consequently alters the spatial patterning of seed deposition under and around the shrub canopy. However, the effect of the presence of shrubs on seed deposition varied, depending strongly on wind direction and sampling position (windward vs leeward sides). The shrub-induced variation in seed deposition was due to the interactive effects of wind direction and sampling position. For example, the presence of shrubs led to a much higher deposition of seeds on the leeward side in all four transects sampled, especially in the most, second-

Table 2. Path analysis of the direct and indirect effects of seed deposition (number of seeds deposited) and seedling emergence (number of seedlings emerged) on plant recruitment (number of plants recruited) in A. squarrosum in the four transects. $\mathrm{R}^{2}$ indicates the proportion of variation in the dependent variable explained by the model in each case. DE $=$ direct effects and IE $=$ indirect effects $\left({ }^{* *} \mathrm{p}\right.$ $\left.<0.01,{ }^{* * *} \mathrm{p}<0.001\right)$.

\begin{tabular}{|c|c|c|c|}
\hline \multirow[t]{2}{*}{ Independent variable } & \multirow[t]{2}{*}{$\mathrm{DE}$ on recruitment $(\mathrm{Y})$} & \multicolumn{2}{|c|}{ IE on recruitment $(Y)$} \\
\hline & & $\mathrm{x}_{1} \rightarrow \mathrm{Y}$ & $\mathrm{x}_{2} \rightarrow \mathrm{Y}$ \\
\hline \multicolumn{4}{|l|}{ Northwest-T ( $\mathrm{n}=72)$} \\
\hline seed deposition $\left(\mathrm{x}_{1}\right)$ & -0.178 & - & -0.051 \\
\hline seedling emergence $\left(\mathrm{x}_{2}\right)$ & $0.522^{* * *}$ & 0.017 & - \\
\hline $\mathrm{R}^{2}$ & $0.314^{* * *}$ & & \\
\hline \multicolumn{4}{|l|}{ West-T $(\mathrm{n}=72)$} \\
\hline seed deposition $\left(\mathrm{x}_{1}\right)$ & $0.303^{* *}$ & - & -0.022 \\
\hline seedling emergence $\left(\mathrm{x}_{2}\right)$ & $0.545^{* * *}$ & -0.012 & - \\
\hline $\mathrm{R}^{2}$ & $0.375^{* * *}$ & & \\
\hline \multicolumn{4}{|l|}{ North-T $(\mathrm{n}=72)$} \\
\hline seed deposition $\left(\mathrm{x}_{1}\right)$ & 0.095 & - & 0.086 \\
\hline seedling emergence $\left(\mathrm{x}_{2}\right)$ & $0.383^{* * *}$ & 0.022 & - \\
\hline $\mathrm{R}^{2}$ & $0.172^{* *}$ & & \\
\hline \multicolumn{4}{|l|}{ Southwest-T ( $\mathrm{n}=72)$} \\
\hline seed deposition $\left(\mathrm{x}_{1}\right)$ & 0.080 & - & 0.061 \\
\hline seedling emergence $\left(\mathrm{x}_{2}\right)$ & $0.757^{* * *}$ & 0.007 & - \\
\hline $\mathrm{R}^{2}$ & $0.589^{* * *}$ & & \\
\hline \multicolumn{4}{|c|}{ Four transects pooled $(\mathrm{n}=288)$} \\
\hline seed deposition $\left(\mathrm{x}_{1}\right)$ & 0.034 & - & 0.037 \\
\hline seedling emergence $\left(\mathrm{x}_{2}\right)$ & $0.574^{* * *}$ & 0.002 & - \\
\hline $\mathrm{R}^{2}$ & $0.333^{* * *}$ & & \\
\hline
\end{tabular}

Northwest- $T$, the transect with the most prevailing wind direction; West- $T$, the transect with the secondary most prevailing wind direction; North-T, the transect with the third most prevailing wind direction; and Southwest-T, the transect with the least prevailing wind direction. 
ary and third most prevailing wind directions (Fig. 2), due to the great differences in wind conditions between the windward and leeward sides. The significantly higher frequency of wind (over $4 \mathrm{~m} \mathrm{~s}^{-1}$ at $2 \mathrm{~m}$ height) on windward side would have a much stronger wind action compared with leeward side. As a result, seeds deposited in the top 5 $\mathrm{cm}$ soil profile located originally in sites near the shrubs on the windward side were re-launched by turbulent eddies from the top soil to the air and carried by wind flow through the shrub canopy and deposited in sites near the shrubs on the leeward side. Thus, fewer seeds were retained on the windward side. In a field study by Yan et al. (2005), they also found that seeds in the $2 \mathrm{~cm}$ soil profile located originally in the lower part of the windward slope in a mobile sand dune were blown away by strong wind and deposited in the upper part of the windward slope, as well as in the leeward slope.

In contrast, there were equivalent number of seeds deposited on both windward and leeward sides of the transect with the least prevailing wind direction. It is possible that wind frequency over $4 \mathrm{~m} \mathrm{~s}^{-1}$ in this transect was so low to re-launch seeds deposited originally on either side of windward or leeward direction. In addition, the stronger wind in the perpendicular direction (more prevailing wind direction) would have similar impacts on the seed deposited on both sides of shrubs in the least prevailing direction.

Generally, observed variation in seed deposition caused by the presence of shrubs was confined within $2 \mathrm{~m}$ from the shrub, despite some marked differences in the range of the shrub's influence across transects and between the windward and leeward sides (Fig. 3). It is most likely correlated with the shrub size. Ben-Natan et al. (2004) reported that the changes caused by an artificial wind barrier made of shadow-cloth (1 $\mathrm{m}$ in height and $4 \mathrm{~m}$ in width) were confined to a range of about $2 \mathrm{~m}$ from the barrier along the main wind direction. In the current study, the shrub size ranged between 63 and $85 \mathrm{~cm}$ in height and between 241 and $310 \mathrm{~cm}$ in canopy diameter, with projected canopy areas of $4.6-7.5 \mathrm{~m}^{2}$.

\section{Effects of shrubs on population dynamics}

Our findings do not rule out the existence of the nurse shrub effect on emergence and establishment of $A$. squarrosum seedlings in all four transects sampled. The lack of the nurse effect in this study may be due to the following factors. Firstly, the recruitment of the pioneer annual $A$. squarrosum in this mobile sandy habitat of the semi-arid Horqin desert does not necessarily depend on nurse effect; instead, this species is capable of colonizing and establishing in bare sandy patches without requiring the moderate conditions existing under shrub canopies, as suggested by a recent study in the semi-arid subtropical Andes (López et al. 2007). Secondly, when seedlings were established in July-August, it was the period when most of rainfall was received in the region. It is unlikely that shrubs would improve the chance of survival for the understorey seedlings as the facilitation of shrubs (nurse effect) is generally expected to occur in more stressful environments (Bertness and Callaway 1994, reviewed by López et al. 2007). On the contrary, we found that there was a marked negative effect of $A$. halodendron shrubs on the establishment of $A$. squarrosum seedlings as evidenced by the fact that the number of $A$. squarrosum seedlings emerged under shrub canopies was lower than in the open locations away from the shrub, especially in the windward side of shrubs in most cases (Fig. 5). In natural ecosystems, facilitation and competition are co-occurring processes in the nurse association (López et al. 2007), and the net effect between the facilitation and competition of shrubs (benefactors) on herb seedlings (beneficiaries) may vary with environmental conditions and identity of interacting species (reviewed by López et al. 2007). The observed negative response of seedling establishment in $A$. squarrosum to the presence of $A$. halodendron shrubs may be due to stronger competitive effects than facilitative effects of nurse shrubs on recruitment. In this mobile sandy habitat, rainfall is readily infiltrate to deep soil profiles, resulting in relatively low availability of soil moisture in the upper layers. As such, this may favour deep-rooted $A$. halodendron while limit the growth and survival of shallow-rooted A. squarrosum seedlings under shrub canopies (Ren et al. 2002). Furthermore, competition for soil water between shrubs and annual plants in the upper layers is also likely to occur as soil moisture in deeper soil profiles would be depleted by shrubs during the long period of dry season over the growing season (Li et al. 2005b).

Our results showed that there were more seeds deposited on leeward side than on windward side in all four transects, but there were fewer seedlings emerged on leeward side than on windward side in three out of the four transects (Fig. 2). This result may suggest an apparent negative density dependence for emergence of seedlings on a local scale. The regression analyses also demonstrated a significant hump-backed relationship between seed density and seedling density, indicating a shift in the seed-seedling relationship from a positive density dependence at lower seed densities to a negative density dependence at higher seed densities (data not shown). However, such densitydependent effects on seedling emergence were specific to wind directions (transects).

No significant relationship was found between the number of seeds deposited and the number of plants recruited in any of the four transects, which suggests that spatial variation in seed deposition did not directly affect recruitment patterning. This is probably due to the fact that recruitment success of annual plants is more strongly determined by the environmental conditions (annual rainfall conditions in particular), especially in water-limited environments (O'Connor and Roux 1995, Zhang et al. 2004b). Another possible explanation for this result may 
be due to the fact that $A$. squarrosum recruitment is most likely to be limited by the availability of safe-sites for germination (Sletvold and Rydgren 2007) rather than seed availability in our system. Further research is therefore needed to determine the relative importance of these two factors. Path analysis further emphasizes the importance of seedling emergence variation in determining the dynamics of the annual herb $A$. squarrosum populations.

\section{Conclusions}

This research provides further evidence of shrubs as a source of spatial heterogeneity in seed availability and therefore an important factor determining the recruitment dynamics of $A$. squarrosum populations in the understorey. However, effects of the presence of shrubs on seed redistribution and deposition were more pronounced in the most prevailing wind direction than in the least prevailing wind direction. Regression and path analyses suggest that seedling emergence rather than seed deposition determined the spatial pattern of $A$. squarrosum populations, but shrubinduced variation in seed availability contributed to observed variation in recruitment indirectly through densitydependent emergence of seedlings. These findings from the current study are important for our understanding of the ecological significance of woody species in driving species coexistence and community dynamics of arid and semi-arid ecosystems.

Acknowledgements - We thank all technicians for field assistance. This work was funded by the Natl Natural Sci. Foundation of China (40771068), and the CAS/SAFEA Int. Partnership Prog. for Creative Res. Teams (CXTD-Z2005-2-4).

\section{References}

Aguiar, M. R. and Sala, O. E. 1997. Seed distribution constrains the dynamics of the Patagonian steppe. - Ecology 78: 93-100.

Barchuk, A. H. et al. 2005. Effect of shrubs and seasonal variability of rainfall on the establishment of Aspidosperma quebracho-blanco in two edaphically contrasting environments. Austral Ecol. 30: 695-705.

Barth, R. C. and Klemmedson, J. O. 1978. Shrub-induced spatial variation of dry matter, nitrogen, and organic carbon. Soil Sci. Soc. Am. J. 64: 635-639.

Belsky, A. J. et al. 1989. The effects of trees on their physical, chemical, and biological environments in a semi-arid savanna in Kenya. - J. Appl. Ecol. 26: 1005-1024.

Ben-Natan, G. et al. 2004. Seeds redistribution in sand dunes: a basis for coexistence of two rodent species. - Oikos 105: 325-335.

Bergelson, J. and Perry, R. 1989. Interspecific competition between seeds: relative planting date and density affect seedling emergence. - Ecology 70: 1639-1644.

Bertness, M. D. and Callaway, R. M. 1994. Positive interactions in communities. - Trends Ecol. Evol. 9: 191-193.
Bullock, J. M. and Moy, I. L. 2004. Plants as seed traps: interspecific interference with dispersal. - Acta Oecol. 25: 3541.

Callaway, R. M. 1992. Effect of shrubs on recruitment of Quercus douglasii and Quercus lobata in California. - Ecology 73: 2118-2128.

Chang, X. L. et al. 1994. The use of Artemisia halodendron in revegetation on degraded sandy grasslands in the Horqin Sandy Land of inner Mongolia.. - J. Desert Res. 16: 27-31.

Charley, J. L. and West, N. E. 1975. Plant-induced soil chemical patterns in some shrub-dominated semi-desert ecosystems of Utah. - J. Ecol. 63: 945-963.

Cross, A. F. and Schlesinger, W. H. 1999. Plant regulation of soil nutrient distribution in the northwestern Chihuahum desert. - Plant Ecol. 145: 11-25.

Cui, J. Y. et al. 2007. Comparison of seed germination of Agriophyllum squarrosum (L.) Moq. and Artemisia halodendron Turcz. Ex Bess, two dominant species of Horqin desert, China. - Arid Land Res. Manage. 21: 165-179.

Dyer, A. R. et al. 2000. Accelerated seedling emergence in interspecific competitive neighbourhoods. - Ecol. Lett. 3: 523529.

Facelli, J. M. and Temby, A. M. 2002. Multiple effects of shrubs on annual plant communities in arid lands of South Australia. - Austral Ecol. 27: 422-432.

Fowler, N. L. 1984. The role of germination date, spatial arrangement, and neighbourhood effects in competitive interactions in Linum. - J. Ecol. 72: 307-318.

Franco, A. C. and Nobel, P. S. 1989. Effect of nurse plants on the microhabitat and growth of cacti. - J. Ecol. 77: 870-886.

Frost, W. E. and Edinger, S. B. 1991. Effects of tree canopies on soil characteristics of annual rangeland. -J. Range Manage. 44: 286-288.

Gómez-Aparicio, L. et al. 2005. Response of tree seedlings to the abiotic heterogeneity generated by nurse shrubs: an experimental approach at different scales. - Ecography 28: 757768.

Gross, K. L. 1990. A comparison of methods for estimating seed numbers in the soil. - J. Ecol. 78: 1079-1193.

Gutiérrez, J.R. et al. 1993. Spatial distribution of soil nutrients and ephemeral plants underneath and outside the canopy of Porlieria chilensis shrubs (Zygophyllaceae) in arid coastal Chile. - Oecologia 95: 347-352.

Henderson, C. B. et al. 1988. Spatial and temporal patterns in the seed bank and vegetation of a desert grassland community. - J. Ecol. 76: 717-728.

Honek, A. et al. 2005. Post-dispersal predation of Taraxacum officinale (dandelion) seed. - J. Ecol. 93: 345-352.

Hook, A. D. et al. 1991. Heterogeneity of soil and plant N and C associated with individual plants and openings in North American shortgrass steppe. - Plant Soil 138: 247-256.

Inouye, R. S. 1980. Density-dependent response by seeds of desert annuals. - Oecologia 46: 235-238.

Kemp, P. R. 1989. Seed banks and vegetation processes in deserts. - In: Leck, M. A. et al. (eds), Ecology of soil seed banks, Academic Press.

Lawes Agricultural Trust. 2006. Genstat Rel. 9.1. VSN International Ltd, Hemel Hempstead, UK.

Li, S. G. et al. 1992. A study of growth characteristics of Agriophyllum squarrosum, a pioneer annual herb on moving sand dunes. Chin. - J. Arid Land Resour. Environ. 6: 63-70 (in Chinese). 
Li, F. R. et al. 2003. Variations of sand transportation rates in sandy grasslands along a desertification gradient in northern China. - Catena 53: 255-272.

Li, F. R. et al. 2005a. The relative importance of pre- and postgermination determinants for recruitment of an annual plant community on moving sandy land. - Ann. Bot. 96: 12151223.

Li, F. R. et al. 2005b. Wind-dispersed seed deposition patterns and seedling recruitment of Artemisia halodendron in a moving sandy land. - Ann. Bot. 96: 69-80.

Li, F. R. et al. 2005c. Patterns of reproductive allocation in $\mathrm{Ar}$ temisia halodendron inhabiting two contrasting habitats. Acta Oecol. 28: 57-64.

Li, F. R. 2007. Presence of shrubs influences the spatial pattern of soil seed banks in desert herbaceous vegetation. J. Veg. Sci. (in press).

López-Pintor, A. et al. 2006. Shrubs as a source of spatial heterogeneity: the case of Retama sphaerocarpa in Mediterranean pasture of cental Spain. - Acta Oecol. 29: 247-255.

López, R. P. et al. 2007. The role of nurse plants in the establishment of shrub seedlings in the semi-arid subtropical Andes. Oecologia 152: 779-790.

Maestre, F. T. et al. 2003. Positive, negative and net effects in grass-shrub interactions in Mediterranean semiarid grasslands. - Ecology 84: 3186-3197.

Miriti, M. N. 2006. Ontogenetic shift from facilitation to competition in a desert shrub. - J. Ecol. 94: 973-979.

Moro, M. J. et al. 1997. Mechanisms of interaction between a leguminous shrub and its understorey in a semi-arid environment. - Ecography 20: 175-184.

Murray, B. R. 1998. Density-dependent germination and the role of seed leachate. - Austr. J. Ecol. 23: 411-418.

Nathan, R. and Muller-Landau, H. C. 2000. Spatial patterns of seed dispersal, their determinants and consequences for recruitment. - Trends Ecol. Evol. 15: 278-285.

Nemoto, M. and Lu, X. Y. 1992. Ecological characteristics of Agriophyllum squarrosum, a pioneer annual on sand dunes in eastern inner Mongolia, China. - Ecol. Res. 7: 183-186

O'Connor, T. G. and Roux, P. W. 1995. Vegetation changes (1949-71) in a semi-arid, grassy dwarf shrubland in the Karoo, South Africa: influence of rainfall variability and grazing by sheep. - J. Appl. Ecol. 32: 612-626.

Orrock, J. L. et al. 2006. Seed predation, not seed dispersal, explains the landscape-level abundance of an early-successional plant. - J. Ecol. 94: 838-845.

Orth, R. J. et al. 2003. Seed-density effects on germination and initial seedling establishment in eelgrass Zostera marina in the Chesapeake Bay region. - Mar. Ecol. Progr. Ser. 250: 7179.

Pugnaire, F. I. and Lázaro, R. 2000. Seed bank and understorey composition in a semi-arid environment: the effect of shrub age and rainfall. - Ann. Bot. 86: 807-813.

Ren, J. et al. 2002. Effect of different microhabitats and stand age on survival of introduced sand-fixing plants. - J. Arid Environ. 51: 413-421.

Rosagno, C. M. et al. 1991. The influence of shrubs on some chemical and physical properties of an aridic soil in northeastern Patagonia, Argentina. - J. Arid Environ. 20:179_ 188.

Russell, S. K. and Schupp, E. W. 1998. Effects of microhabitat patchiness on patterns of seed dispersal and seed predation of Cercocarpus ledifolius (Rosaceae). - Oikos 81: 434-443.

Schurr, F. M. et al. 2005. A mechanistic model for secondary seed dispersal by wind and its experimental validation. - J. Ecol. 93: 1017-1028.

Seginer, I. 1975. Flow around a wind break in oblique wind. Bound-Lay Meterol. 9: 133-141.

Shumway, S. W. 2000. Facilitative effects of a sand dune shrub on species growing beneath the shrub canopy. - Oecologia 124: 138-148.

Sletvold, N. and Rydgren, K. 2007. Population dynamics in Digitalis purpurea: the interaction of disturbance and seed bank dynamics. - J. Ecol. (in press).

Tielbörger, K. and Valleriani, A. 2005. Can seeds predict their future? Germination strategies of density-regulated desert annuals. - Oikos 111: 235-244.

Vetaas, O. R. 1992. Micro-site effects of trees and shrubs in dry savannas. - J. Veg. Sci. 3: 337-344.

Yan, Q. et al. 2005. Structure, pattern and mechanisms of formation of seed banks in sand dune systems in northeastern inner Mongolia, China. - Plant Soil 277: 175-184.

Zhang, H. et al. 2004a. Wind regime and resultant sand-transporting potential of Naiman Banner in Horqin sandy land during the past five years. - J. Desert Res. 24: 623-628 (in Chinese with English abstract).

Zhang, J. G. et al. 2004b. Ecological adaptation strategies of annual plants in artificial vegetation-stabilized sand dunes in Shapoyou region. - Sci. China, Ser. D 47(suppl. 1): 5060.

Zhao, L.Y. et al. 2003. Characteristics of soil seed bank and standing vegetation changes in sandy grasslands along a desertification gradient. - Acta Ecol. Sin. 23:1745-1756. 